\title{
ANALISIS KRIMINOLOGI TERHADAP USAHA PERDAGANGAN TANPA SURAT IZIN (STUDI KASUS PERIZINAN TOKO OBAT)
}

\author{
Askarial, S.H., M.H. \& Delpi Susanti, S.IP
}

\begin{abstract}
Evaluation is the process of comparing the standard to the facts and analyzing the results. The extent to which the policy achieves its goals and objectives. To be better, public policy is the decision made by the State, especially the government as a strategy to realize the objectives of the State concerned, the service is a process of the activities of a person or group of people to provide assistance optimally to others requiring both requested and unsolicited. Drug Definitions are materials or alloys of materials including biological products used to influence or investigate physiological or pathological systems. The Drug Store is selling drugs without requiring the pharmacist to exist or without a doctor's prescription, while the pharmacy is a store that sells products that are under a doctor's prescription or pharmacist. Related to that through Article 4 of Regional Regulation No. 12 of 2008 on the Distribution of License Nuisance mention the ordinance for the maintenance of drug store permits. For the indicator the authors use the indicator of KEPMENPAN No. 64 Year 2004, the location of research that is writer fokuskan dikota pekanbaru with type of research that is descriptive quantitative.
\end{abstract}

Keywords : Implementation, Service, Permit Drug Store.

\section{Pendahuluan}

Pelanggaran izin dalam melakukan kegiatan usaha dan bisnis menjadi marak terjadi di kota-kota besar, yang mana menjadi perhatian serius bagi pemerintah. Pada kenyataannya pelanggaran dalam izin kegiatan usaha ini menjadi berkembang pesat ditiap-tiap kota.

Pada umumnya Pelanggaran merupakan sebuah perilaku yang melanggar aturan-aturan yang berlaku serta norma-norma yang berlaku dalam masyarakat. Banyak kita lihat dan sadari bahwa pelanggaran menjadi sebuah hal yang biasa dianggap banyak orang yang padahal dampak dari pelanggaran itu bisa berbahaya dan sangat berdampak pada hal lainnya yang bisa merugikan orang lain. Pelanggaran bukan hanya diartikan sebagai perilaku seorang remaja yang melakukan pelanggaran lampu merah atau aturan lalu lintas, namun di dalam penelitian ini, 
pelanggaran dilihat dari suatu kegiatan untuk melakukan usaha atau berbisnis seperti bisnis usaha waralaba.

Pelanggaran dalam melakukan kegiatan usaha dan bisnis di era modern ini marak terjadi, banyak sekali kita melihat pembangunan pasar modern yang menyebar luas keseluruh plosok negeri yang merupakan tempat perbelanjaan masyarakat, yang mana pembangunan yang menjadi tempat berjumpanya penjual dan pembeli ini seharusnya lebih nyaman, aman, dan akan perlindungan dari hukum. Namun banyak sekali para pengusaha yang mendirikan tempat dagang atau usaha, namun tidak memiliki izin dari pemerintah, hal ini yang menjadi perhatian oleh pemerintah untuk di tindak lanjuti.

Masalah pelanggaran SIUP menjadi sebuah fenomena yang merugikan pemerintah, dan juga masyarakat, pelanggaran SIUP ini marak terjadi, yang mana mereka banyak melakukan perdagangan usaha dan bisnis yang melanggar aturan hukum dan peraturan daerah.

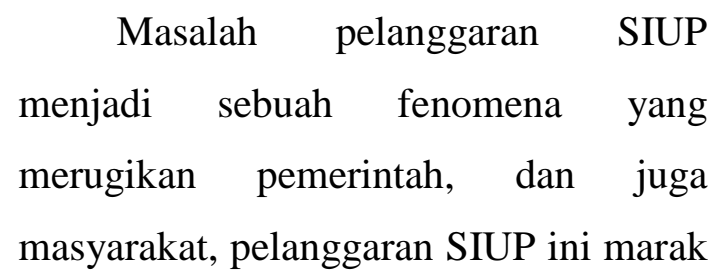

terjadi, yang mana mereka banyak melakukan perdagangan usaha dan bisnis yang melanggar aturan hukum dan peraturan daerah.

Sebagai suatu daerah otonom, Pemerintah Daerah Kota Pekanbaru telah menjalankan berbagai kebijakan dalam pemberian pelayanan kepada masyarakat, salah satu urusan yang dijalankan oleh Pemerintah Daerah Kota Pekanbaru adalah Bidang Kesehatan, adapun tugas pokok dari Kantor Dinas Penanaman Modal dan Pelayanan Terpadu Satu Pintu Kota Pekanbaru, yaitu :

1. Perencanaan Program-Program Kesehatan dengan Pendekatan Peningkatan Kesehatan (Promotif), pencagahan penyakit (preventif), pengobatan penyakit (kuratif) dan pemulihan kesehatan (rehabilitatif).

2. Pembinaan manajemen kesehatan daerah yang meliputi perencanaan, pelaksanaan dan pengendalian kebijakan kesehatan.

3. Pembinaan pengawasan operasional dan pengendalian atas pengelolaan pelayanan kesehatan pada fasilitas-fasilitas kesehatan baik pemerintah maupun swasta serta fasilitas non kesehatan yang 
mempunyai pengaruh kepada kesehatan masyarakat.

4. Pengupayaan pemberdayaan masyarakat dalam bidang kesehatan.

5. Perencanaan dan pembinaan pelayanan kesehatan keluarga, pelayanan media KB dan Gizi Masyarakat.

6. Perencanaan, pembinaan, pelaksanaan pengamatan, pencegahan dan pemberantasan penyakit dan penanganan kejadian luarbiasa bidang kesehatan.

7. Perencanaan, pembinaan dan pelaksanaan upaya kesehatan lingkungan dan pemantauan dampak pembangunan terhadap kesehatan kesehatan lingkungan dan pemantauan dampak pembangunan terhadap kesehatan lingkungan.

8. Perencanaan dan pengadaan obat untuk Puskesmas dan jaringan serta pengawasan sarana dan sediaan farmasi disarana pelayanaan swasta.

9. Pengawasan makanan dan minuman yang berpotensi menimbulkan masalah kesehatan masyarakat dari proses produksi sampai dengan peredarannya.
10. Pembinaan, pengawasan dan pengendalian sarana pelayanan kesehatan dasar dan rujukan baik pemerintah maupun swasta.

11. Penyusunan, pelaksanaan dan pengembangan sistem kesehatan daerah.

12. Pengembangan sistem pembiayaan kesehatan melalui jaminan pemeliharaan kesehatan masyarakat atau sistem lain.

13. Pembinaan dan pengawasan mutu pelayanan kesehatan dasar dan rujukan

14. Perencanaan, pelaksanaan dan pembinaan pelayanan kesehatan bagi masyarakat miskin.

15. Penanggulangan masalah kedaruratan dan bencana

16. Perencanaan penyelenggaraan dan pengembangan sistem informasi kesehatan daerah.

17. Perencanaan, pengembangan, dan pendayagunaan sumberdaya kesehatan

18. Perencanaan, pelaksanaan dan pengembangan promosi kesehatan. Dari sejumlah fungsi dinas sebagaimana dijelaskan diatas maka salah satu fungsi yang sangat penting dari Kantor Dinas Penanaman Modal dan Pelayanan Terpadu Satu Pintu Kota 
Pekanbaru adalah Pembinaan pengawasan operasional dan pengendalian atas pengelolaan pelayanan kesehatan pada fasilitas-fasilitas kesehatan baik pemerintah maupun swasta serta fasilitas non kesehatan yang mempunyai pengaruh kepada kesehatan masyarakat.

Dari fungsi ini terlihat sejumlah kegiatan baik yang dilakukan oleh pemerintah atau pun oleh pihak swasta. Sehubungan dengan kegiatan yang dilakukan oleh pemerintah atau pun oleh pihak swasta. Sehubungan dengan kegiatan penyiapan fasilitas kesehatan tersebut, melalui pasal 6 penyiapan fasilitas kesehatan tersebut, melalui pasal 4 Peraturan Daerah Nomor 8 tahun 2012 tentang Retribusi Izin Gangguan yang menegaskan sebagai berikut :

1. Setiap orang pribadi/ badan yang mendirikan dan menyelenggarakan sarana pelayanan kesehatan dan yang akan bekerja pada pelayanan kesehatan didaerah, wajib memiliki izin Pemerintah Daerah.

2. Izin penyelenggaraan sarana pelayanan kesehatan swasta terdiri dari :

- Izin balai pengobatan

- Izin rumah bersalin

- Izin optik
- Izin rumah sakit

- Izin tanda nomor sertifikat penyuluhan industri rumah tangga makanan dan minuman

\section{- Izin toko obat}

- Izin apotik

- Izin salon

- Izin praktek dokter umum/ dokter gigi

- Izin praktek spesialis

- Izin praktek bidan atau perawat

- Izin fisioterapi

- Pendaftaran pengobatan tradisional

- Izin laboratorium

- Izin praktek berkelompok dokter spesialis/ dokter gigi spesialis

- Izin operasional pest control, termite control dan fumigasi

3. Surat Keterangan/Rekomendasi

- Surat keterangan Baik sehat TTU/TPM, tokoh peptisida dan mobil tinja

- Surat keterangan lahir dari puskesmas

- Rekomendasi perizinan institusi sarana pelayanan kesehatan swasta

4. Untuk memperoleh izin sebagaimana dimaksud pada ayat 1 diatas permohonan harus mengajukan permohonan secara 
tertulis kepada Kepala Kantor Dinas Kesehatan Pekanbaru dengan pedoman persyaratan yang akan diatur lebih lanjut oleh Kepala Kantor Badan Pelayanan Terpadu dan Penanaman Modal Kota Pekanbaru.

5. Pemohon sebagaimana dimaksud pada ayat 3 dipersamakan dengan Surat Pemberian Tagihan Retribusi Daerah

6. Izin sebagaimana ayat 1 diatas baru dapat diberikan setelah retil ditetapkan, dilunasi ke khas daerah c/ Kepala Dinas Kesehatan Kota Pekanbaru

7. Apabila dianggap perlu permohonan izin sebagaimana dimaksud pada ayat 3 dapat disebut perjanjian yang berhubungan dengan norma-norma sosial yang berlaku.

Dari pasal 4 Peraturan Daerah Nomor 8 tahun 2012 tentang Retribusi Izin Gangguan salah satunya adalah Rekomendasi izin toko obat, yang menjadi fokus penelitian yang dilakukan penelti yaitu bagian Surat Izin Usaha Perdagangan yang dalam hal ini Toko Obat yaitu izin gangguan sesuai dengan yang tertera pada Peraturan Daerah Kota Pekanbaru No. 8 Tahun 2012, dimana arti penting bidang ini karena toko atau depot obat adalah distribusi obat-obatan pada masyarakat, bila toko obat tidak memiliki izin usaha, hal ini tentu akan membahayakan masyarakat karena ada toko obat tidak terawasi oleh pemerintah, juga bagi yang tidak mengurus izin usaha akan mengurangi bagi pemerintah daerah kota pekanbaru sumber-sumber pendapatan Anggaran Daerah dari aspek penerimaan retribusi.

Pelanggaran SIUP ini dilakukan oleh toko obat yang berada di jalan Karya Mandiri, Kelurahan Maharatu, Kecamatan Marpoyan Damai. Kejadian ini terjadi ketika pengelola toko tidak melakukan pembuatan Izin Usaha Perdagangan yang terkait dengan peraturan daerah Kota Pekanbaru No. 7 Tahun 2000 tentang Izin Tempat Usaha. Namun sebelumnya pihak toko dan Camat setempat sudah di berikan surat peringatan berdasarkan surat dari kepala Dinas Penanaman Modal dan Pelayanan Terpadu Satu Pintu (DPM-PTSP) Kota Pekanbaru, namun terkesan tidak diindahkan. Sehingga pihak dari Instasi Satuan Polisi Pamong Praja (SATPOL PP) untuk melakukan penutupan paksa atau penyegelan ruko tempat usaha dan bisnis perusahaan tersebut agar tidak 
mendirikan tempat usaha toko obat tersebut.

Dengan diharapkannya dari pengawasan dan ketertiban yang akan dilakukan oleh Badan Pemerintah Daerah, agar hal tersebut tidak akan ada lagi sebuah tempat-tempat usaha, khusunya Toko Obat yang didirikan tanpa memiliki izin usaha tersebut. Karena apabila Pemerintah Daerah atau Badan yang terkait tidak melakukan penertiban pada Alfamart yang tidak memiliki izin, akan menjadi menyebar luas atau akan semakin banyak disetiapsetiap daerah, baik Kota, Kabupaten sampai ke Kacamatan, dan hal tersebut akan berdampak kepada masyarakat usaha kecil, yaitu akan mengurangi hasil pendapatan pada pedagang usaha kecil menengah.

Dalam hal ini jelas bahwa perusahaan yang melakukan perdagangan usaha dan bisnis ini atau tempat pasar modern, telah melakukan pelanggaran yang merugikan pemerintah, dan masyarakat sesuai dengan ketentuan hukum, baik hukum pemerintah maupun hukum dalam daerah Yaitu berdasarkan keputusan Menteri Perindustrian Dan Perdagangan Republik Indonesia Nomor : 70/MDAG/PER/12/2013. Tentang Pedoman
Penataan Dan Pembinaan Pasar Tradisional, Pusat Perbelanjaan Dan Toko Modern. Dalam pasal 24 yang berbunyi : pelaku usaha yang melakukan kegiatan usaha dibidang pasar tradisional, pusat perbelanjaan dan toko modern wajib memiliki izin usaha sebagai legalitas. Izin usaha yang dimaksud seperti

1. IUPPT Untuk Pasar Tradisional

2. IUPP Untuk Pertokoan, Mall, Plasa, dan Pusat Perdagangan

3. IUTM Untuk Minimarket, Supermarket, Departement Store, Hypermarket, dan Perkulakan.

Dalam keterangan peraturan dari Dinas Perindustrian Dan Perdagangan Republik Indonesia, bahwa setiap individu wajib membuat izin usaha dalam melakukan kegiatan usaha di setiap daerah. Dan adapun aturan dari Dinas Perindustrian Dan Perdagangan Republik Indonesia tentang wajib membuat izin usaha yaitu di jelaskan dalam aturananya nomor 77/MDAG/PER/12/2013. Tentang Penerbitan Surat Izin Usaha Perdagangan dan Tanda Daftar Perusahaan Secara Simultan Bagi Perusahaan Perdagangan.

Proses penyelesaian perizinan yang merupakan proses internal yang dilakukan oleh pegawai atau petugas. 
Pada umumnya permohonan izin harus dapat melengkapi berkas persyaratan terlebih dahulu, mengetahui prosedur pelayanan yang ditentukan oleh pemerintah kecamatan selaku pemberi izin. Untuk alur pelayanan dalam pengurusan izin usaha rumah makan, dimulai dari permohonan mengajukan izin sampai kepada tahapan diterbitkannya izin, terdapat beberapa tahapan sebagai berikut:

\section{Skema Prosedur Pelayanan}

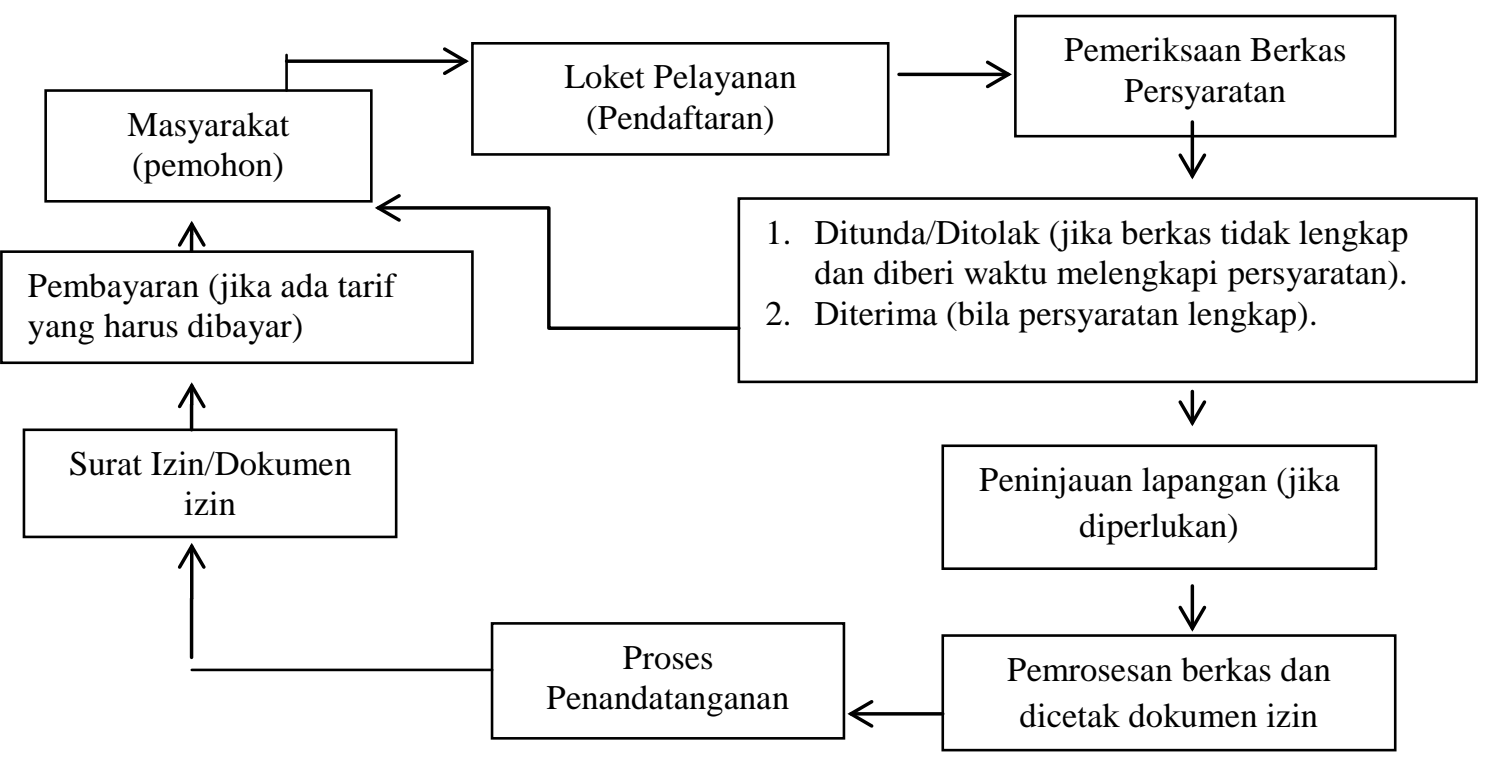

Sumber: Data Olahan Peneliti 2017.

Berikut ini bisa dilihat jumlah pemohon yang sudah pernah mengurus izin usaha Toko Obat di Kota Pekanbaru sebagai berikut:

Tabel 2

Tabel I.2 : Jumlah anggota masyarakat yang mengurus surat izin toko obat Tahun 2012/2017

\begin{tabular}{|c|l|l|c|c|}
\hline No & Nama Toko Obat & \multicolumn{1}{|c|}{ Alamat } & Ya & Tidak \\
\hline $\mathbf{1}$ & \multicolumn{1}{|c|}{$\mathbf{2}$} & \multicolumn{1}{|c|}{$\mathbf{3}$} & $\mathbf{4}$ & $\mathbf{5}$ \\
\hline 1. & Fajar Farma & $\begin{array}{l}\text { Jl. Kaharuddin Nasution, Marpoyan } \\
\text { Damai }\end{array}$ & & - \\
\hline 2. & Dharma Jaya & $\begin{array}{l}\text { Jl. Kaharuddin Nasution, Marpoyan } \\
\text { Damai }\end{array}$ & & - \\
\hline 3. & Rossa & $\begin{array}{l}\text { Jl. Kaharuddin Nasution, Marpoyan } \\
\text { Damai }\end{array}$ & & - \\
\hline 4. & Cipta Karya & Jl.Cipta Karya & & - \\
\hline 5. & Sakura & Jl. Cipta Karya & $\checkmark$ & - \\
\hline 6. & M21 & Jl. Cipta Karya ujung & & \\
\hline
\end{tabular}




\begin{tabular}{|c|c|c|c|c|}
\hline 7. & Alif_Han & Jl. Taman Karya & & - \\
\hline 8. & Refiana & Jl. Taman Karya & & - \\
\hline 9. & Dorganda & Jl. Taman Karya & & - \\
\hline 10. & HZA & Jl. Taman Karya & & - \\
\hline 11. & Novita & Jl. Bukit Raya & & - \\
\hline 12. & Maju Farma & Jl. Bukit Barisan Ujung & & - \\
\hline 13. & Darma Jaya & Jl. Garuda & & - \\
\hline 14. & Tiara & Jl. Paus ujung Arifin No.4 & $\checkmark$ & \\
\hline 15. & Sehat Bersama & Jl. Tangkerang Timur, Tenayan raya & & - \\
\hline 16. & Cahaya & Jl. Ir.H. Juanda No.120 & & - \\
\hline 17. & Asia & Jl. Ir.H. Juanda No.91 & & - \\
\hline 18. & Sumber Baru & Jl. Ir.H. Juanda No. 67 & & - \\
\hline 19. & Sumber & Jl. Ir.H. Juanda No. 15 & & - \\
\hline 20. & Sumber Rezeki & Jl.. Prof M. Yamin & & - \\
\hline 21. & Penawar & Jl. Teratai No. 67 & & - \\
\hline 22. & Bintang Jaya & Jl. Pepaya No. 64 A pekanbaru & $\checkmark$ & \\
\hline 23. & Favorit & Jl. Adi Sucipto & & - \\
\hline 24. & Fernando & Jl. Impres / Kartama & & - \\
\hline 25. & Putri farma & Jl. Arengka & & - \\
\hline 26. & Gloris & Jl. Paus No. 45 pekanbaru & & - \\
\hline 27. & Al-sofi & Jl. Duku pekanbaru & & - \\
\hline 28. & Rajawali & Jl. Rajawali sakti & & - \\
\hline 29. & Naufal & Jl. Impres/ Kartama & & - \\
\hline 30. & Mamy pharma & Jl. Inpres No.100f & & - \\
\hline 32. & Beringin farma & $\begin{array}{l}\text { Jl. Soekarno hatta No.63 Pasar pagi } \\
\text { arengka }\end{array}$ & $\checkmark$ & \\
\hline 33. & Mustika & Jl. Angkasa gg. raya No.19 C & $\checkmark$ & \\
\hline 34 & Tiga Saudara & Jl. T. Bey gg. Puspa No. 12 pekanbaru & $\checkmark$ & \\
\hline 35. & Anugrah & Jl. Durian pasar palapa & $\checkmark$ & \\
\hline 36. & Sakanti & Jl. H. Imam munandar No. 352 & $\checkmark$ & \\
\hline 37. & SY. Medika & Jl. Panjaitan No. 10D & $\checkmark$ & \\
\hline 38. & Zain & Jl. Tanjung Datuk No. 141 & $\checkmark$ & \\
\hline 39. & Jonan & Jl. Imam Munandar & $\checkmark$ & \\
\hline 40. & Ikhtiar Farama & Jl. Hantuah No. 87 A & $\checkmark$ & \\
\hline 41. & Sumber Waras & Jl. Juanda No. 80 & $\checkmark$ & \\
\hline 42. & Yossy & Jl. Pepaya No. 18 & $\checkmark$ & \\
\hline 43. & Berkah & Jl. Sepakat & $\checkmark$ & \\
\hline 44. & Panca Sehat & Jl. Cokro Aminoto No. 151 & $\checkmark$ & \\
\hline 45. & Zia Farma & $\begin{array}{l}\text { Jl. Cipta Karya ujung simpang jl. Datuk } \\
\text { Tunggal }\end{array}$ & $\checkmark$ & \\
\hline 46. & Kartini Farma & Jl. Paus No. 50 & $\checkmark$ & \\
\hline 47. & Bima farma & Jl. H.Imam Munandar No. 116 & $\checkmark$ & \\
\hline 48. & Garuda Farma & Jl. Garuda No. 83 & $\checkmark$ & \\
\hline 49. & Mustika & Jl. Angkasa gg. Raya No. 19 & $\checkmark$ & \\
\hline 50. & Amanah & Jl. Tuanku Tambusai No.3 & $\checkmark$ & \\
\hline
\end{tabular}

Sumber : Kantor Dinas BPTPM/ DPMPTSP Pekanbaru 
Dapat dilihat bahwa jumlah pemohon dalam pengurusan izin usaha rumah makan dari tahun 2012 s/d 2017 hanya berjumlah 22 (dua puluh dua) Toko Obat saja.

Konsep-Konsep Tinjauan Kriminologi

Dalam Pelanggaran Izin Usaha Toko Obat

Sutherland (Santoso dan Zulfa, 2010:11) merumuskan kriminologi sebagai keseluruhan ilmu pengetahuan yang bertalian dengan perbuatan jahat sebagai gejala sosial (The body of knowledge regarding crime as a sosial phenomenon). Menurut Sutherland, kriminologi mencakup proses-proses pembuatan hukum, pelanggaran hukum dan reaksi atas pelanggaran hukum. Kriminologi olehnya dibagi menjadi tiga cabang ilmu utama yaitu:

a. Sosiologi hukum. Kejahatan itu adalah perbuatan yang oleh hukum dilarang dan diancam dengan suatu sanksi. Jadi yang menentukan bahwa suatu perbuatan itu adalah kejahatan adalah hukum. Di sini menyelidiki faktor-faktor apa yang menyebabkan perkembangan hukum (khususnya hukum pidana).

b. Etiologi kejahatan. Merupakan cabang ilmu kriminologis yang mencari sebab musabab dari kejahatan. Dalam kriminologis, etiologi kejahatan merupakan kejahatan paling utama.

c. Penology. Pada dasarnya ilmu tentang hukuman, akan tetapi Sutherland memasukkan hak-hak yang berhubungan dengan usaha pengendalian kejahatan represif maupun preventif.

Masalah kejahatan (Dermawan, 2013:1) adalah salah satu masalah sosial yang selalu menarik dan menuntut perhatian yang serius dari waktu kewaktu. Terlebih lagi menurut aasumsi umur serta beberapa hasil pengamatan dan penelitian berbagai pihak, dari waktu kewaktu, terdapat kecendrungan perkembangan peningkatan dari bentuk dan jenis kejahatan tertetu, baik secara kualitas maupun kuantitas.

Surat Izin Usaha Perdagangan (SIUP) adalah surat izin untuk dapat melaksanakan kegiatan usaha perdagangan. Setiap perusahaan, koperasi, persekutuan maupun perusahaan perseorangan, yang melakukan kegiatan usaha perdagangan wajib memperoleh SIUP yang diterbitkan berdasarkan domisili 
perusahaan dan berlaku di seluruh wilayah Republik Indonesia.

Surat izin usaha perdagangan merupakan sebuah aturan dari peraturan pemerintah sesuai dengan PP No .65 tahun 2001 tentang pajak daerah. Berdasarkan UU dan PP tersebut pemerintah daerah diberikan kewenangan untuk melakukan perubahan terhadap masing-masing jenis pajak. Penetapan ini didasarkan pada pertimbangan bahwa pajak tersebut secara umum dapatt dipungut hampir disemua daerah dan merupakan jennis pungutan yang secara teoritis dan praktek merupakan pungutan yang baik (Syofiarti, 2008:89).

\section{Tabel II.2 Kerangka Pemikiran Pelanggaran Surat Izin Usaha Perdagngan Toko}

Obat di Kota Pekanbaru.

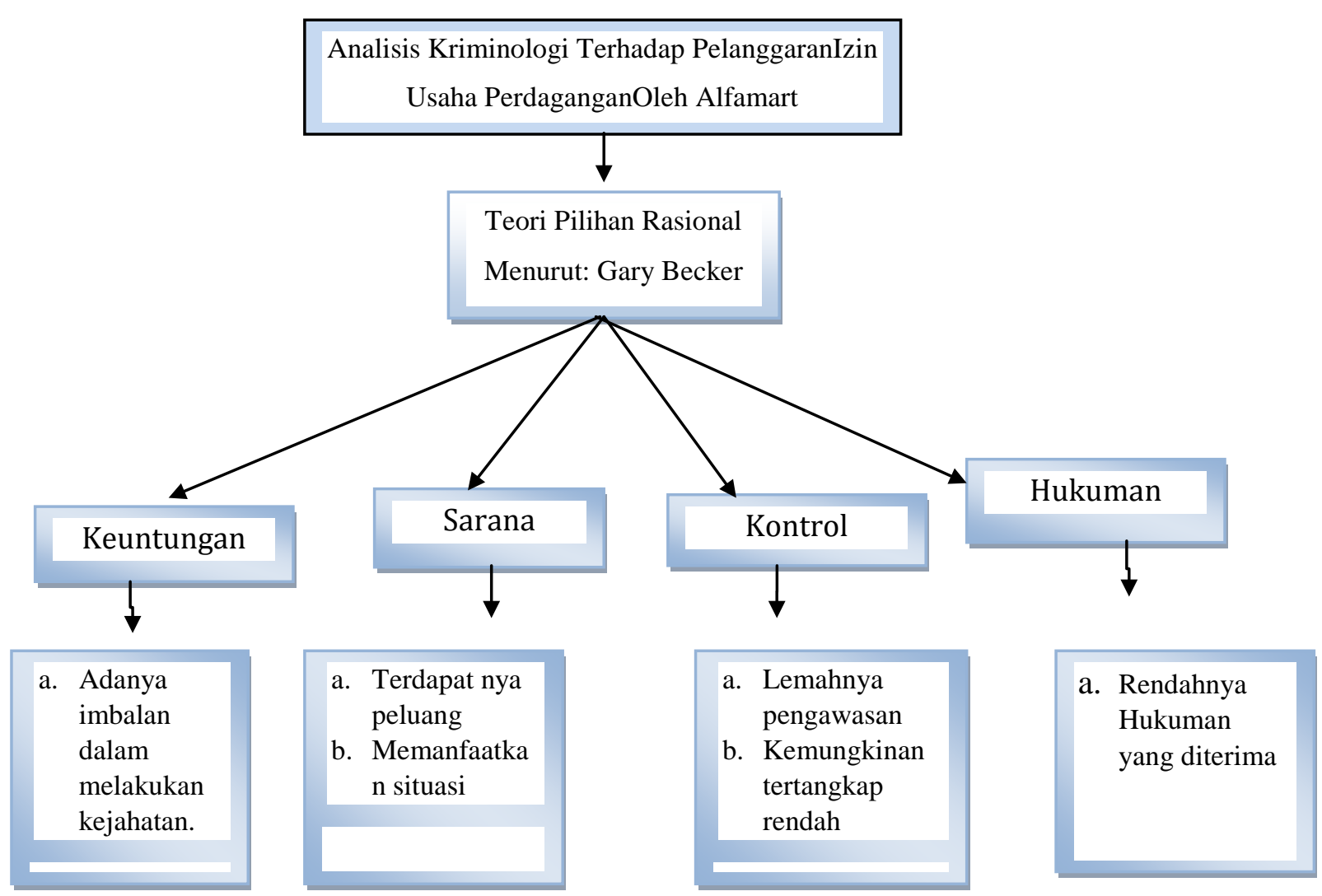

Sumber : Olahan Peneliti, 2017 


\section{METODE PENELITIAN}

Penelitian ini menggunakan metode kualitatif dengan tipe penelitian deskriptif. Penelitian ini bukan mengumpulkan data sekali jadi dan kemudian mengolahnya, malainkan tahap demi tahap dan disimpulkan selama proses berlansung dari awal sampai akhir kegiatan yang bersifat naratif.

Penelitian dengan pendekatan kualitatif menekankan analisis proses dari proses berpikir secara induktif yang berkaitan dengan dinamika hubungan antar fenomena yang diamati, dan senantiasa menggunakan logika ilmiah. Penelitian kualitatif bertujuan mengembangkan konsep sensitivitas pada masalah yang dihadapi, menerangkan realitas yang berkaitan dengan penelusuran teori dari bawah (grounded theory) dan mengembangkan pemahaman akan satu atau lebih dari fenomena yang dihadapi.

Peneliti dalam penelitian kualitatif mencoba mengerti makna suatu kejadian atau peristiwa dengan mencoba berinteraksi dengan orang-orang dalam situasi/fenomena tersebut. Tujuan penelitian kualitatif adalah untuk menemukan jawaban terhadap suatu fenomena atau pertanyaan melalui aplikasi prosedur ilmiah secara sistematis dengan menggunakan pendekatan kualitatif.

Dalam melakukan penelitian ini penulis memilih objek penelitian pada Pelanggaran Toko Obat yang ada di pekabaru sesuai dengan pelayanan kepengurusan dibawah Dinas Penanaman Modal dan Pelayanan Terpadu Satu Pintu yang terletak di Kota Pekanbaru. Pertimbangan kenapa Kantor DPMPTSP, karena peneliti menganggap kantor ini layak untuk diteliti sebab banyak hal yang menyebabkan belum optimalnya penyelenggaraan Pemberian izin tersebut, mulai dari tidak jelasnya persyaratan dan prosedur untuk memperoleh pelayanan, prilaku petugas yang belum bersifat melayani, serta tidak jelasnya waktu dan biaya yang diperlukan untuk mendapatkan pelayanan. Disamping itu adapun alasan pemilihan lokasi tersebut, karena wilayah tersebut terus mengalami perkembangan khususnya untuk usaha Toko Obat. Untuk itu, pemerintah daerah Kota Pekanbaru mengharapkan agar kecamatan dapat memainkan perannya dalam mengoptimalkan Perizinan Toko Obat yang bersentuhan langsung kepada 
masyarakat sebagai pemilik usaha. Dengan demikian diharapkan untuk mampu memberikan hasil yang sesuai dengan harapan masyarakat.

Untuk menentukan sumber informasi dalam penelitian ini maka peneliti menggunakan Puposive Sampling. Dimana peneliti akan memilih informan yang dianggapmengetahui informasi dan masalahnya secara mendalam dan dapat dipercayamenjadi sumber data yang mantap yang mempunyai keterkaitan dengan halyang akan diteliti, mengetahui dan terlibat langsung maupun mempunyaipengaruh dalam penelitian. Adapun yang menjadi key informen dalam penelitian ini adalah Kepla DPMPTSP. Sedangkan yang menjadi informan yaitu Pemilik Toko Obat yang memiliki izin dan yang tidak memiliki izin,. Untuk mengetahui siapa saja sumber informasi dalam penelitian ini dapat dilihat sebagai berikut:

1. Kepala DPMPTSP : 1 orang

2. Kabag Toko Obat : 1 orang

3. Toko Obat yang berizin : 22 orang

4. Masyarakat mengurus izin : 55 orang

\section{HASIL DAN PEMBAHASAN} Gambaran Umum Kecamatan Bangko Pusako

Secara geografis, posisi Kota Pekanbaru terletak $101^{\circ} 14^{\prime}-101^{0} 34$ ' bujur timur dan ${ }^{0} 25-0^{0} 45$ lintang utara, keadaanya relatif merupakan daerah dataran rendah dengan struktur tanah pada umumnya terdiri dari jenis aluvial dengan pasir, sementara pinggiran kota terdiri dari jenis tanah organosol dan humus yang merupakan rawa-rawa yang bersifat asam.

Luas kota Pekanbaru saat ini \pm 446,50 km², Kota Pekanbaru dibelah oleh sungai siak yang membentang dari barat ke timur, yang juga merupakan jalur perhubungan lalu lintas perekonomian rakyat.

Batas-batas daerah Kota Pekanbaru adalah :

Sebelah utara : Kabupaten siak dan kabupaten Kampar

Sebelah selatan: Kabupaten kampar dan kabupaten pelalawan

Sebelah timur : Kabupaten Siak dan Kabupaten Pelalawan

Sebelah Barat : Kabupaten Kampar.

\section{Analisis Kriminologi Terhadap Usaha Perdagangan Tanpa Surat Izin (Studi Kasus Perizinan Toko Obat)}

Dari hasil wawancara dengan kepala bagian yang mengurus surat rekomendasi izin toko obat dikantor badan pelayanan terpadu dan penanaman modal kota pekanbaru, terdapat hal-hal yang mempengaruhi dalam pemberian pelayanan, itu dikarenakan pegawai/aparatur yang bertugas didalam pengurusan surat rekomendasi izin toko obat sangat sedikit jumlahnya, dan tugas 
yang di emban/di atasi banyak. Sehingga menjadikan proses pelayanan menimbulkan masalah atau proses menjadi lamban.

\section{Faktor-Faktor Penghambat Analisis} Kriminologi Terhadap Usaha Perdagangan Tanpa Surat Izin (Studi Kasus Perizinan Toko Obat).

Pengurusan surat rekomendasi izin toko obat yang dilakukan pata kantor badan pelayanan terpadu dan penanaman kota pekanbaru pada dasarnya bertujuan untuk membantu kelancaran masyarakat untuk mengurus surat rekomendasi izin toko obat didaerah kota pekanbaru bagi masyarakat yang membutuhkannya. Surat rekomendasi izin toko obat dibutuhkan bagi masyarakat yang ingin membuka usaha toko obat. Oleh sebab itu, pihak kantor badan pelayanan terpadu dan penanaman modal kota pekanbaru dapat memberikan pelayanan yang baik dan lancar.

Adapun faktor-faktor yang dapat berpengaruh pada pelaksanaan pelayanan dalam pengurusan surat rekomendasi izin toko obat antara lain adalah sebagai berikut :

1. Ketersediaan sumberdaya manusia, tersedianya para petugas yang melaksanakan pelayanan sesuai dengan benar serta memiliki kemampuan kerja dan profesionalisme yang tinggi akan menjamin terciptanya mutu pelayanan yang baik.

2. Kedisiplinan kerja, aparatur pemerintah yang bertugas menyelenggarakan pelayanan publik seperti hal pelayanan pengurusan surat rekomendasi izin toko obat harus dapat menerapkan kedisiplinan yang tinggi sehingga penyelesaian proses pelayanan dapat berjalan tepat waktu sesuai dengan ketentuan yang berlaku.

3. Pengawasan atasan . pihak pimpinan atasan mulai kela seksi, kepala bagian hingga kepala kantor perlu melakukan pengawasan terhadap pelaksanaan kerja bahawan untuk menghindari terjadinya penyimpangan atau kesalahan dan kebijakan pelayanan yang telah ditetapkan sehingga proses pelayanan dapat berlangsung sebagaimana mestinya.

4. Ketersediaan sarana dan prasarana, tersedianya sarana dan prasarana yang lengkap dan dengan kebutuhan tugas dan pekerjaan akan mendukung kelancaran proses pelayanan. 


\section{Kesimpulan}

Dari hasil wawancara dengan kepala bagian yang mengurus surat rekomendasi izin toko obat dikantor badan pelayanan terpadu dan penanaman modal kota pekanbaru, terdapat hal-hal yang mempengaruhi dalam pemberian pelayanan, itu dikarenakan pegawai/aparatur yang bertugas didalam pengurusan surat rekomendasi izin toko obat sangat sedikit jumlahnya, dan tugas yang di emban/di atasi banyak. Sehingga menjadikan proses pelayanan menimbulkan masalah atau proses menjadi lamban.

\section{Saran}

Agar pelayanan publik di kantor Badan Pelayanan Terpadu dan Penanaman Modal Kota Pekanbaru mengenai pengurusan surat rekomendasi izin toko obat dapat lebih dimaksimalkan lagi dimasa mendapatang, maka pihak pimpinan sebaiknya dapat :

1. Membina kemampuan kerja aparatur yang bertugas dalam memberikan pelayanan pada proses pengurusan surat rekomendasi izin toko obat agar mampu memberikan pelayanan secara maksimal kepada masyarakat.
2. Menyesuaikan kebutuhan sumberdaya manusia yang bertugas dalam memberikan pelayanan dengan beban tugas dan pekerjaan yang sesuai sehingga peyelenggaraan tugas pelayanan dapat berlangsung dengan baik dan lancar.

3. Melakukan pengawasan dan pengarahan terhadap para bawahan serta mensosialisasikan kebijakan pelayanan secara lebih efektif dan memberikan arahan kepada bawahan untuk dapat bekerja secara baik, menjaga kedisiplinan dan profesional dalam bekerja agar pelayanan dapat berjalan sebagaimana yang diharapkan.

\section{Daftar Pustaka}

Abbdusalam. 2007, Kriminologi. Jakarta : PT. Restu Agung

Aziz, Azwar, 2009. Jurnal Ilmu Hukum, Volume 1, Pekanbaru: Fakultas Hukum Universitas Islam Riau.

Daryanto. 2013. Strategi dan Tahapan Mengajar. Bandung: CV Yrama Widya.

Dermawan, Moh. Kemal. 2000, Teori Kriminologi, Cetakan Pertama. Jakarta : Universitas Terbuka

Dermawan, Moh. Kemal. 2013, Strategi Pencegahan Kejahatan, Edisi Pertama. Jakarta : FISIP UI.

Hasan, Alwi. 2005.KamusBesarBahasa Indonesia.Jakarta : BalaiPustaka 
Masdiana, Erlangga, 2006. kejahatan dalam Wajah Pembangunan, Cetakan Pertama. Jakarta: Nfu Publishing.

Mustofa, Muhammad. 2007, Metodologi Penelitian Kriminologi, Edisi Kedua. Jakarta: FISIP UI Press.

Nitibaskara, Tb. Ronny Rahman, 2009. Perangkap Penyimpangan dan Kejahatan. Jakarta: Yayasan Pengembangan Kajian Ilmu Kepolisian

Riduwan, 2014. Metode dan teknik menyusun proposal penelitian. Cetakan Keenam. Bandung : Alfabeta Bandung

Ritzer, George dan Douglas J.Goodman. 2003.TeoriSosiologi Modern. Jakarta: Prenada Media

Samas, Nandang, 2010. Pengantar Kriminologi. CV Prisma Esta Utama. Bandung

Santoso, Topo. 2003, Kriminologi. Jakarta : Rajawali Perss

Santoso, Topo dan Eva Achjani. 2010, Krimminologi. PT. Raja Grafindo Persada, Jakarta

Samosir, C, Djisman, 2012. Sekelumit Tentang Penologi dan Permasyarakatan. Jakarta. Nuansa Aulia

Suyanto,

(2005).MetodePenelitianSosial:

Bagong. BergabaiAlternatifPendekatan. Jakarta :Prenada Media

Syofiarti, 2008. Jurnal Mahkamah, Volume 20. Pekanbaru: Fakultas Hukum Universitas Islam Riau.
Wirawan, Ida, Bagus, 2012. Teori Teori Sosial dalam Tiga Paradigma. Edisi Pertama. Jakarta: Kencana Prenada Media Group.

Yusuf, A. Muri. 2014. Metode Penelitian: Kuantitatif, Kualitatif dan Penelitian Gabungan. Jakarta, PT Fajar Interpratama.

Duun, William N. 2003, Analisis Kebijakan Publik, Yogyakarta : Hanindita Graha Widya

Hamdi, Muklis 2006. Memahami ilmu pemerintahan. Jakarta, Raja Grafindo Persada

\section{Peraturan Perundang-Undangan}

Undang-undang No. 23 Tahun 2014

Tentang Pemerintahan Daerah.

Peraturan Daerah Kota Pekanbaru Nomor 8 Tahun 2012 Tentang Retribusi Izin Gangguan

Peraturan Pemerintah Republik Indonesia Nomor 65 Tahun 2005 Tentang Pedoman Penyusunan dan Penetapan Standar Pelayanan Minimal

Peraturan Mentri dalam Nomor 79 Tahun 2007 Tentang Pedoman Penyusunan Rencana Pencapaian Standar Pelayanan Minimal

Peraturan Daerah Kota Pekanbaru Nomor 5 Tahun 2004 Tentang Retribusi Pelayanan dan Perizinan dibidang Kesehatan. 